\title{
COMPARATIVE STUDY OF UVA-RADIATION AND ILLUMINANCE OF WHITE TUBULAR FLUORESCENT LAMPS FOR DIFFERENT BRANDS IN SAUDI ARABIA MARKET
}

\author{
Manal A. Haridy ${ }^{1}$, Khadigjah R. Alreshidy ${ }^{2}$, Ghazia S. Alazmi ${ }^{3}$ \\ ${ }^{1}$ Photometry and Radiometry Division, National Institute of Standards (NIS), Giza, Egypt \& Physics \\ Department, College of Science, University of Hail (UOH), Hail, Kingdom of Saudi Arabia (KSA) \\ ${ }^{2}$ Physics Department, College of Science, University of Hail (UOH), Hail, Kingdom of Saudi Arabia (KSA) \\ ${ }^{3}$ Physics Department, College of Science, University of Hail (UOH), Hail, Kingdom of Saudi Arabia (KSA)
}

\begin{abstract}
Lighting is a major use of energy in schools and universities. White Tubular Fluorescent Lamps (WTFLs) are lit mainly Hail university faculties and administration buildings. As the use of WTFLs becomes increasingly widespread so also increases the concerns relating to their mercury content and the associated hazards. While the risk associated with individual WTFLs is generally concerned negligible, the cumulative impact of millions of WTFLs does however becomes a more significant issue and could represent a potential risk to the environment. The present study aimed to focus on three different brands of white tubular fluorescent lamps (WTFLs) which are the most useable lamps in the Saudi Arabia markets and evaluate the relationships between $U V$ emissions radiated and illuminance. Various parameters such as ultra violet irradiance (UVA), ratio of UVA irradiance to electrical power $(\eta)$ and ratio of UVA power to luminous flux $(K)$, for the four of WTFLs are studied to dedicate their performance. A set up based on UVA/B silicon detector for irradiance measurements in UVA region. Second set up for Luxmeter is used for measuring illuminance. For all three different brands under study, K parameter remains less than the safe limit for human health. YAMANY -18-60 cm Watt WTFLs have the smaller ratio (n) than Philips 18 Watt -60 cm WTFLs. ELETRA -36 Watt $-120 \mathrm{~cm}$ WTFLs have the smaller ratio (n) than Philips 36 Watt $-120 \mathrm{~cm}$ WTFLs. According to our results, we recommended using YAMANY - 18 Watt than Philips 18 Watt at short distance in table lamps or other applications and the distance more than 0.5 meter. Also, we recommended using ELETRA -36 Watt than Philips 36 Watt at short distance in table lamps or other applications and the distance more than 1 meter. Data analysis was performed and uncertainty model includes all parameters accompanied with the measurements are calculated.
\end{abstract}

Keywords: White Tubular Fluorescent Lamps (WTFLs), Illuminance, UVA Radiation, Irradiance, Uncertainty.

\section{INTRODUCTION}

Fluorescent Lamps play an important role in both industrial and domestic lighting is one of the most obvious and easiest methods to achieve energy efficiency [1]. One of the most important technologies in this century is energy saving that is an important item among the concept of environmental protection, economy, and improved science and technology [2].There are various energy-saving products and Tubular Fluorescent Lamps is one of these products.

The fluorescent lamp is an arc discharge through a mixture of mercury and a rare gas, generally argon. The mercury gas, the active gas, has an operating pressure of the order of $6-10 \times 10^{-3}$ torr. The rare gas, a buffer gas has an operating pressure of the order of 3 torr. The conducting species of the discharge are electrons and mercury ions. In addition the discharge yields a number of excited mercury atoms. These excited atoms yield a copious quantity of photons of 253.7 and $185 \mathrm{~nm}$ UV radiations. These are resonant radiations from the mercury atom. The phosphor on the inner wall of the encapsulating glass tube is in turn excited by these UV photons and fluoresces in the visible spectrum. The phosphors used in these light sources are designed to yield white light for a general source of illumination. The fluorescent lamp is designed as a cylindrical tube with a large aspect ratio as shown in Figure 1 and the diameter of the tube is of the order of $16-40 \mathrm{~mm}$ with lengths ranging from $13.5-250 \mathrm{~cm}$. [3].

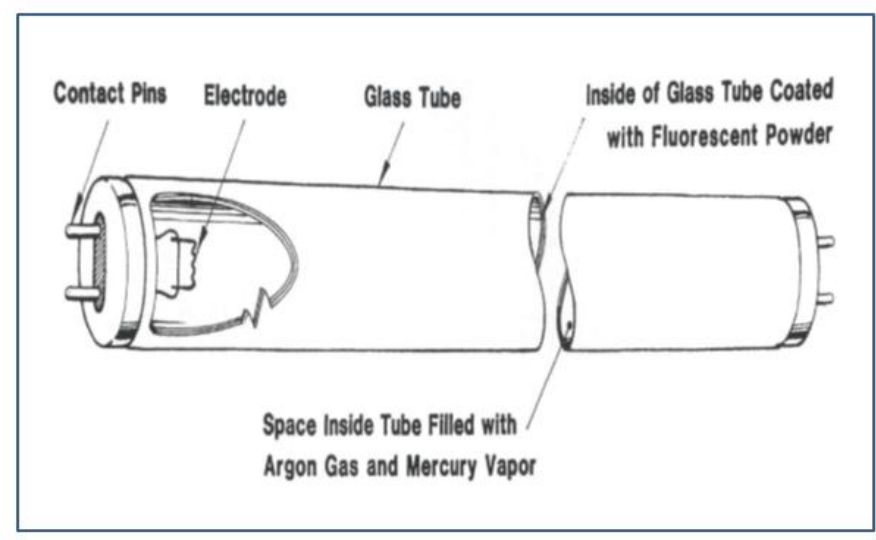

Fig 1. Typical Tubular Fluorescent Lamp Showing Electrode Mount Structure [3]. 
The widespread use of Tubular Fluorescent Lamps is followed by people concerns about their light qualities and health risks. One of the disadvantages of Tubular Fluorescent Lamps emits higher acceptable levels of ultraviolet (UV) radiation [4-6]. Tubular Fluorescent light bulbs contain mercury, and the inside of the tube is coated with phosphors; the mercury gas inside the tube becomes excited when the electric current is switched on which emits UV radiation. This UV radiation then interacts with the chemicals on the inside of the bulb to generate light. Ideally, conversion of UV to visible light should be $100 \%$; however, due to the defect in phosphor it contains trace amount of UV radiation [5,7-11]. To emphasis on use of energy saver Tubular Fluorescent Lamps, it is necessary to analyze the effect of radiation especially UV radiation on human health. UV radiation light has three wavelength regions UVA (315 $\mathrm{nm}-400 \mathrm{~nm})$, UVB (280 nm-315 nm) and UVC (200 nm$280 \mathrm{~nm}$ ) [12-16]. Light output in the Tubular Fluorescent Lamps is influenced by the mercury vapor pressure inside the lamp; if the pressure is either greater than or less than optimal, light output declines, and change in contain mercury vapor can change light output [17]. Under normal use, the UV emission at distance $65 \mathrm{~cm}$ from Tubular Fluorescent Lamps would not produce a significant UV hazard [18].

\subsection{Theoretical Principles of Illuminance}

The relation between the measured illuminance and the lamp intensity is given by the following relation:

$$
E=\frac{I \cos \theta}{d^{2}}
$$

where $\mathrm{E}$ is the illuminance, I the intensity, $\mathrm{d}$ the distance between the lamp and the receiving surface and $\theta$ the angle between the normal of the receiving surface and the direction of emission[19].

\subsection{Theoretical principles of UVA Irradiance}

Spectral irradiance in UVA region is defined as the power of electromagnetic radiation per unit area in $\left(\mathrm{W} / \mathrm{m}^{2} / \mathrm{nm}\right)$ hence,

$$
\text { UVA irradiance } I_{\lambda}(\lambda)=\int_{\lambda_{1}}^{\lambda_{2}} I(\lambda) d \lambda
$$

where, $I_{\lambda}(\lambda)$ is spectral irradiance in $\left(\mathrm{W} / \mathrm{m}^{2} / \mathrm{nm}\right)$. On the other hand, spectral power distribution (SPD) measurement describes the power per unit area per unit wavelength of an illumination. More specifically, the concentration is a function of wavelength to any radiometric quantity or photometric quantity [20].

UVA irradiance per unit electrical power is defined as [12]

$$
\eta=\frac{\int_{\lambda_{1}}^{\lambda_{2}} E_{\lambda}(\lambda) d \lambda}{P}
$$

Ultraviolet radiation power per unit lumen output is defined as [12]

$$
K=\frac{\int_{\lambda_{1}}^{\lambda_{2}} E_{\lambda}(\lambda) d \lambda}{k_{m} \int_{380 n m}^{780 n m} E_{\lambda}(\lambda) d \lambda V d \lambda}
$$

$E_{\lambda}(\lambda)$ is spectral distribution of the radiant flux $W / \mathrm{nm}$ $V(\lambda)$ is spectral luminous efficiency.

$k_{m}$ is photometric radiation equivalent $(683 \mathrm{~lm} / \mathrm{W})$.

From equation (1) $\mathrm{k}$ is also defined as:

$$
K=\frac{\int_{\lambda_{1}}^{\lambda_{2}} I_{\lambda}(\lambda) d \lambda}{k_{m} \int_{380 n m}^{780 n m} I_{\lambda}(\lambda) d \lambda V d \lambda}
$$

UV radiation in the output light of Tubular Fluorescent Lamps has to be analyzed for its safe use, especially for indoor lighting, where the distance between the lamp and human being is small. One of the important parameters for analyzing the effect of Tubular Fluorescent Lamps on human health is UV irradiance (UV power per unit area), which depends on the distance between the source and area of exposure [12]. In the present research, measurements of the irradiance and illuminance to determine various parameters such as ultra violet irradiance (UVA), ratio of UVA irradiance to electrical power $(\eta)$ and ratio of UVA power to luminous flux $(\mathrm{K})$, for different types of White Tubular Fluorescent Lamps (WTFLs), which we use it at Hail University to light class rooms and offices, are studied to dedicate their performance and accompanied standard uncertainties are evaluated. UVA portion will be only concerned and the ratio of UV power to luminous flux is considered to be equal to the ratio of UV irradiance to illuminance $[5,12,21]$.

\section{METHOD}

In the present research, the study of four types of White Tubular Fluorescent Lamps (WTFLs) which are the most usable in Saudi Arabia market. The first type is $18 \mathrm{Watt}$ and $60 \mathrm{~cm}$ length - YAMANY company (UOH-WTFL-1), the second type is 18 Watt and $60 \mathrm{~cm}$ length - Philips company (UOH-WTFL-2), the third type is 36 Watt and $120 \mathrm{~cm}$ length - Philips company (UOH-WTFL-3) and the fourth type is 36 Watt and $120 \mathrm{~cm}$ length - ELETRA company (UOH-WTFL-3). Before testing, the lamps were seasoned $100 \mathrm{~h}$ in vertical base-down position [19]. Different parameters such as ultra violet irradiance (UVA), ratio of UVA irradiance to electrical power $(\eta)$, ratio of UVA power to luminous flux $(\mathrm{K})$ and relative spectral power distribution), four types of White Tubular Fluorescent Lamps (WTFLs) are studied to dedicate their performance. Measurements were performed in a conditioned dark room with the conditioned surfaces according to the International 
Commission on Non-Ionizing Radiation Protection (ICNIRP) recommendations [22] and maintaining the temperature at $(25 \pm 2)^{\circ} \mathrm{C}$ at distance 0.5 meter and 1 meter. The photometric bench consists of Sper Scientific UVA/B Light Meter (Model 850009C) as shown in Figure 2 and calibrated at National Institute of Standard and Technology (NIST), USA. The UVA detector was mounted on a translation stage and positioned at the same height as the light source (White Tubular Fluorescent Lamps (WTFLs)) on the optical bench. Prior taking measurements, each White Tubular Fluorescent Lamps (WTFLs) were warmed up to 30 minutes. Measurements were repeated for each lamp and were finally averaged out and the uncertainty in irradiance measurements is calculated.

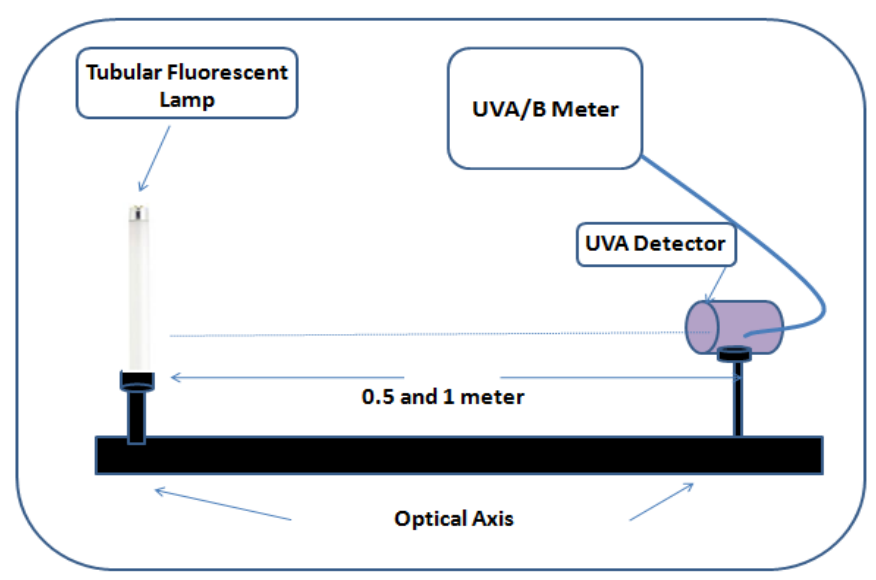

Fig 2. Schematic diagram for measuring UVA irradiance using calibrated radiometer.

The illuminance of each lamp is measured using a Luxmeter TM-201Lux as shown in Figure3. Measurements were performed in a conditioned dark room and maintaining the temperature at $(25 \pm 2)^{\circ} \mathrm{C}$ at distance 0.5 meter and 1 meter. Measurements were carried out on a photometric bench in a dark room. The Luxmeter was mounted on a translation stage and positioned at the same height as the light source (White Tubular Fluorescent Lamps (WTFLs)) on the optical bench. Prior to taking measurements, each White Tubular Fluorescent Lamps (WTFLs) was warmed up to 30 minutes. Measurements were repeated for each lamp and were finally averaged out and the uncertainty in irradiance measurements is calculated.

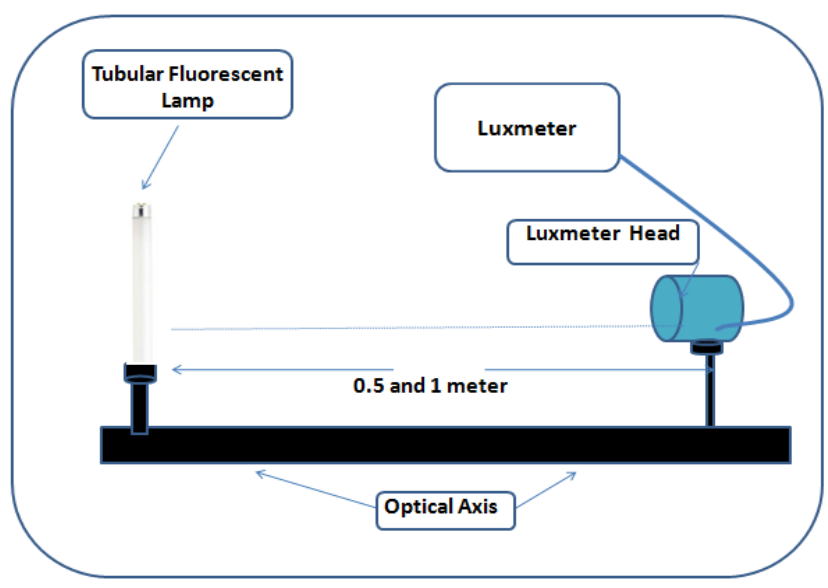

Fig 3. Schematic diagram for measuring illuminance for White Tubular Fluorescent Lamps (WTFLs).

\section{RESULTS AND DISCUSSIONS}

In this research, measurements of UVA content present in the radiation of three different brands of white tubular fluorescent lamps (WTFLs) commonly used in Saudi Arabia markets and Hail University in indoor lighting. The description of these lamps as the following: YAMANY - 18 Watt and $60 \mathrm{~cm}$ length (UOH-WTFL-1), Philips -18 Watt and $60 \mathrm{~cm}$ length (UOH-WTFL-2), Philips - 36 Watt and $120 \mathrm{~cm}$ (UOH-WTFL-3) and - ELETRA 36 Watt and 120 $\mathrm{cm}$ length (UOH-WTFL-4). All the lamps are studied to assess their unwanted output in the UVA region and their Illuminance level at distance 0.5 meter and 1 meter. These lamps are designed to emit their power in the visible region. In fact, they emit almost of their energy in the visible region but part of their energy is emitted in the UV region.

The irradiance level of each lamp measured at 0.5 meter and 1 meter distance for all the white tubular fluorescent lamps (WTFLs) from its central vertical axis using UVA radiometer. The quantities presented in Figures 4 and 5 at 0.5 meter and 1 meter distance for all the white tubular fluorescent lamps (WTFLs) respectively. The UVA irradiance at 0.5 meter distance for all lamps varies from $3 \mu \mathrm{W} / \mathrm{m}^{2}$ to $8 \mu \mathrm{W} / \mathrm{m}^{2}$ and at 1 meter distance for all lamps varies from zero to $3 \mu \mathrm{W} / \mathrm{m}^{2}$. Our results showed that increase the distance from WTFLs, results in to reduce the level of UV exposure. 


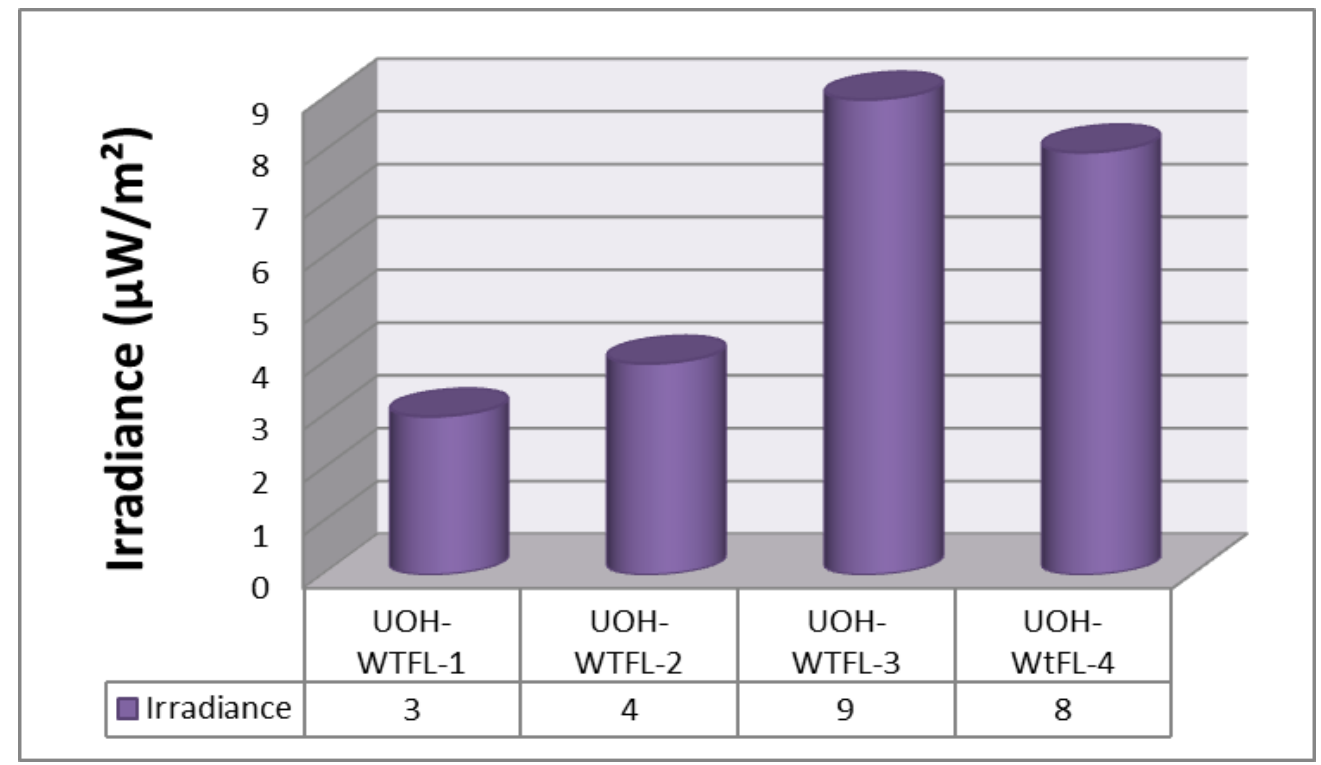

Fig 4. UVA absolute irradiance levels WTFLs using calibrated UVA radiometer at 0.5 meter.

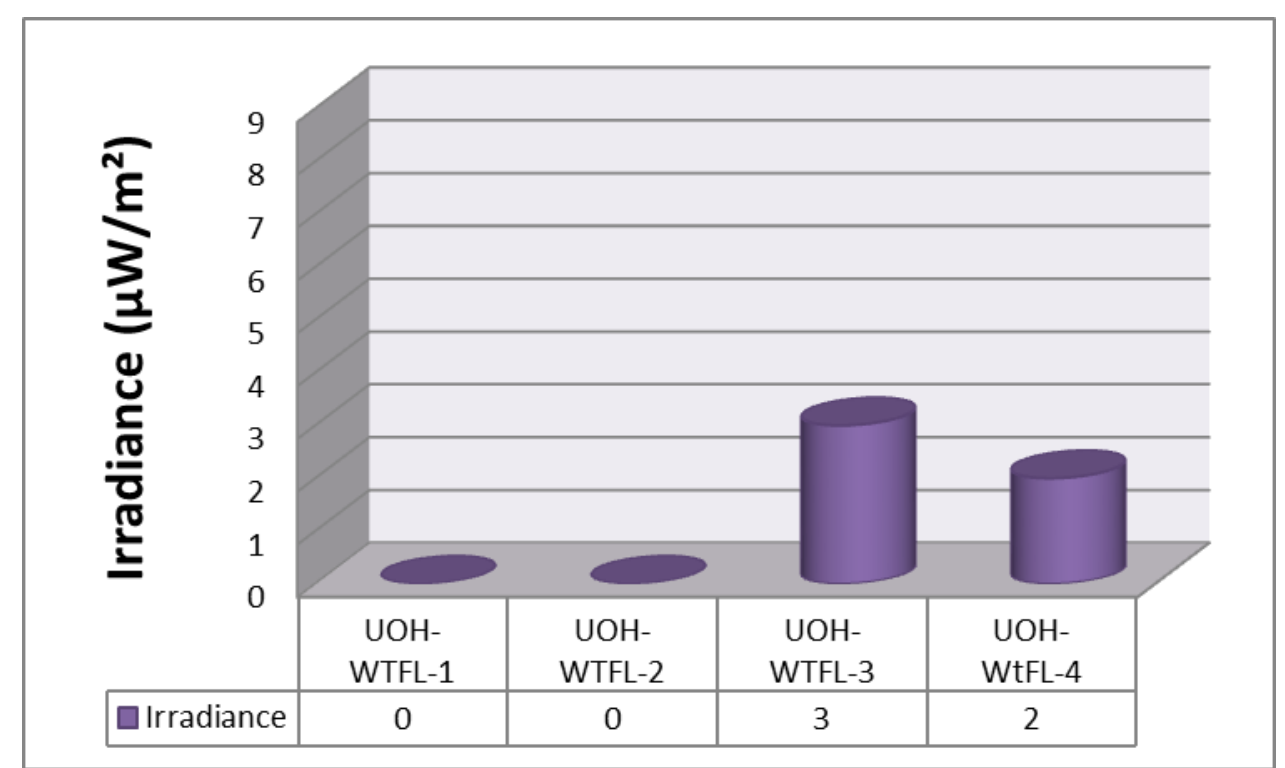

Fig 5. UVA absolute irradiance levels for WTFLs using calibrated UVA radiometer at 1 meter.

To make a better comparison in UV concentration, it would be more appropriate to analyze UVA irradiance per electrical wattages $(\eta)$. In general $[12,21]$, the value of $(\eta)$ should remain invariant, provided the phosphor and the mercury content used in WTFLs are in the same proportion. Also, large variation may due to non-uniformity in coating of phosphor. Smaller value of $(\eta)$ is safe for human being. Figures 6 and 7 show the histogram for comparison of UVA absolute irradiance levels per to electrical power of $(\eta)$ at 0.5 meter and 1 meter distance for all the white tubular fluorescent lamps (WTFLs) respectively. The value of $(\eta)$ at 0.5 meter distance for all lamps varies from $0.167 \mathrm{~m}^{-2}$ to $0.25 \mathrm{~m}^{-2}$ and the value of $(\eta)$ at 1 meter distance for all lamps varies from zero to $0.056 \mathrm{~m}^{-2}$. 


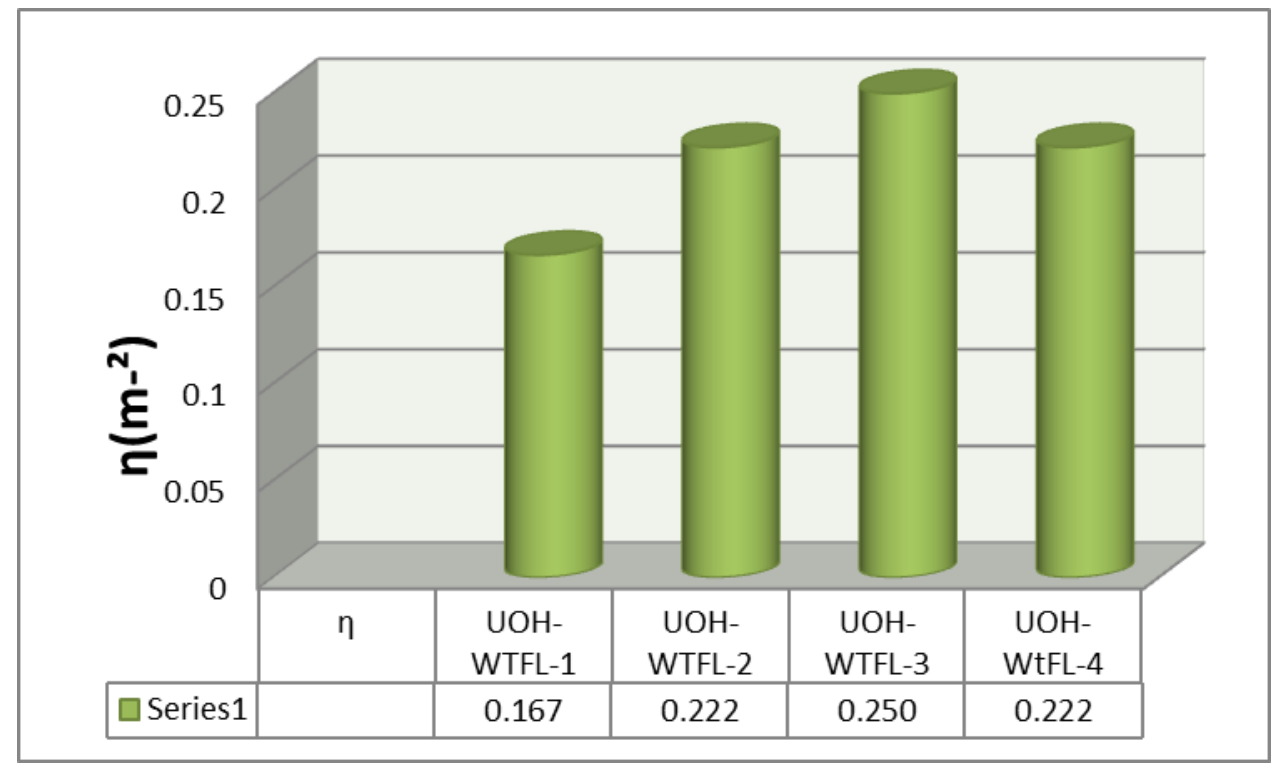

Fig 6. UVA absolute irradiance levels per to electrical power of WTFLs $(\eta)$ at 0.5 meter.

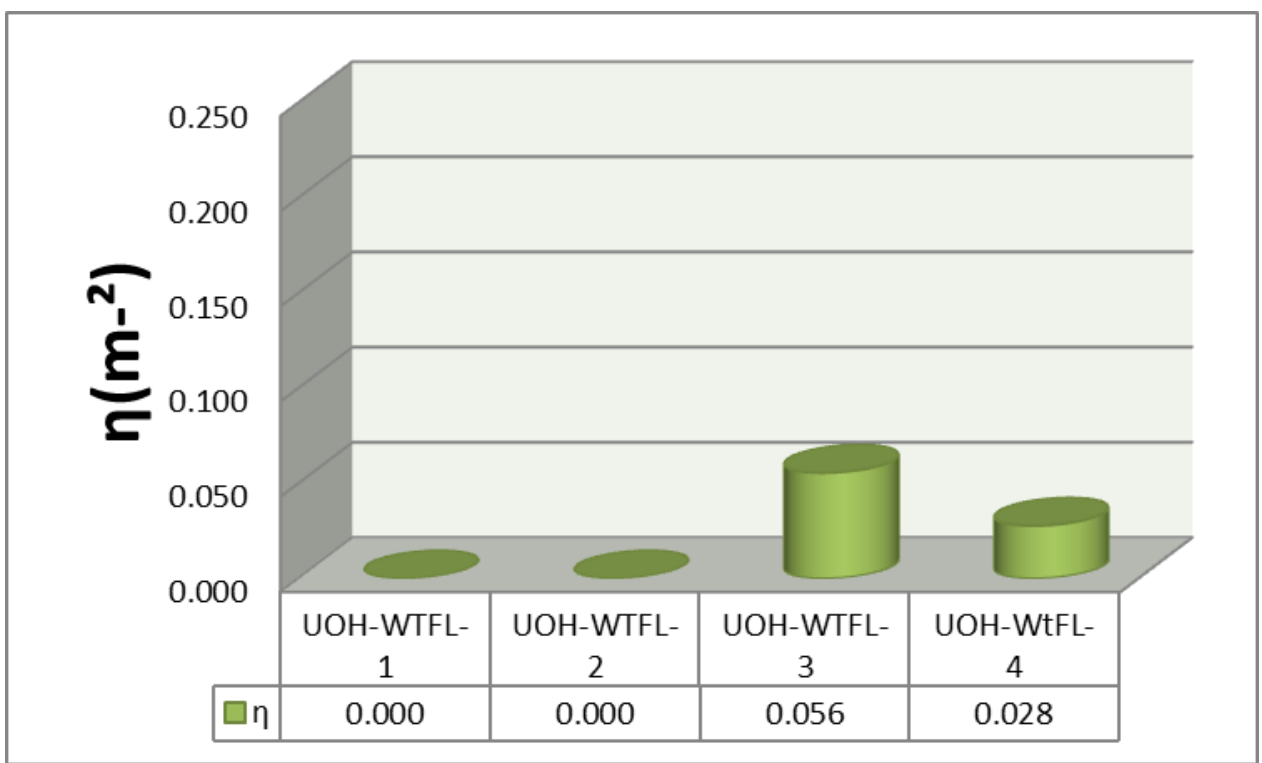

Fig 7. UVA absolute irradiance levels per to electrical power of WTFLs ( $\eta)$ at 1 meter.

UVA irradiance to illuminance ratio $(\mathrm{K})$, is of more interest for analyzing the WTFLs radiation characteristics. The amount of illuminace for WTFLs is measured at 0.5 meter and 1 meter distance for all the WTFLs and the quantities presented in Figures 8, 9 as ratio $\mathrm{k}$ which is UVA absolute irradiance levels per illuminace values for WTFLs. Figures 8, 9 show the histogram for comparison of UVA absolute irradiance levels per illuminace values $(\mathrm{K})$ for at 0.5 meter and 1 meter distance for all the white tubular fluorescent lamps (WTFLs) respectively. The values of $(\mathrm{K})$ at 0.5 meter distance for all lamps varies from $0.0068 \mu \mathrm{W} / \mathrm{lm}$ to $0.0102 \mu \mathrm{W} / \mathrm{lm}$ and the values of (K) at 1 meter distance for all lamps varies from zero to $0.009 \mu \mathrm{W} / \mathrm{lm}$. The maximum detected value $0.0102 \mu \mathrm{W} / \mathrm{lm}$ is less than the safe limit for human health $[12,21]$. 


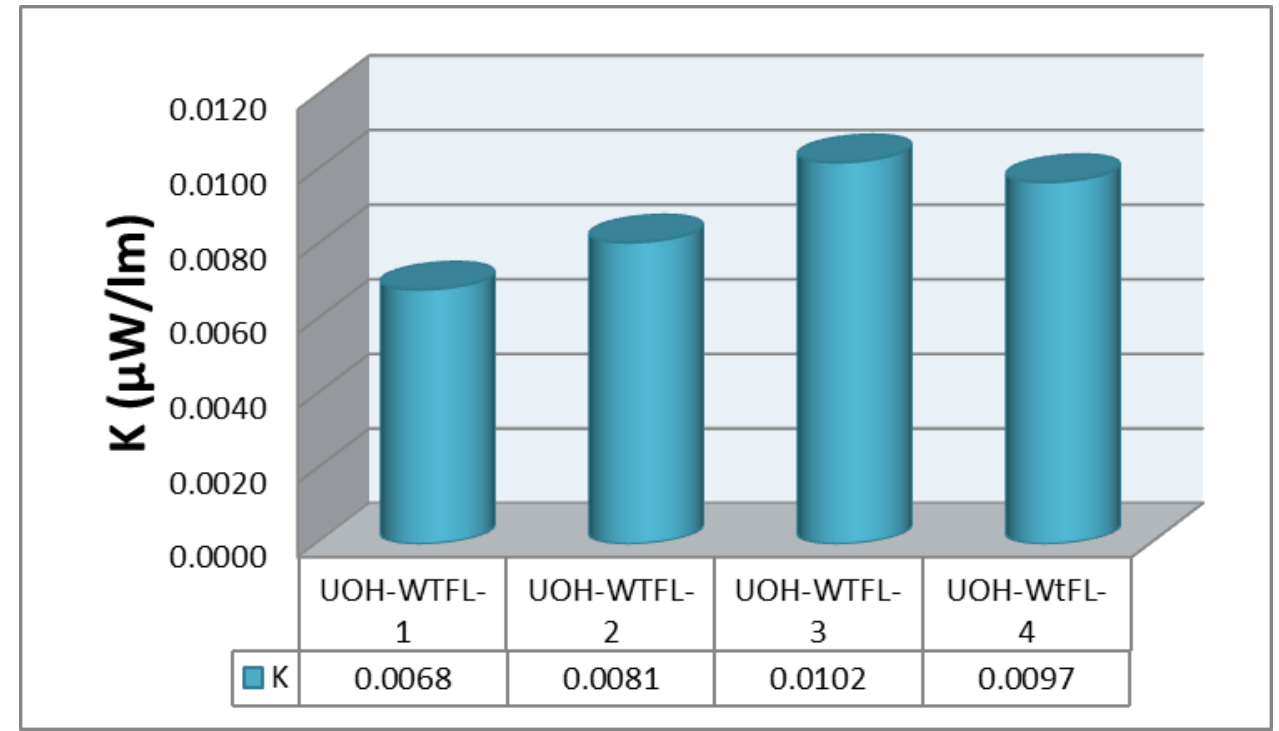

Fig. 8. UVA absolute irradiance levels per illuminace values (K) for WTFLs using calibrated UVA radiometer and luxmeter at 0.5 meter.

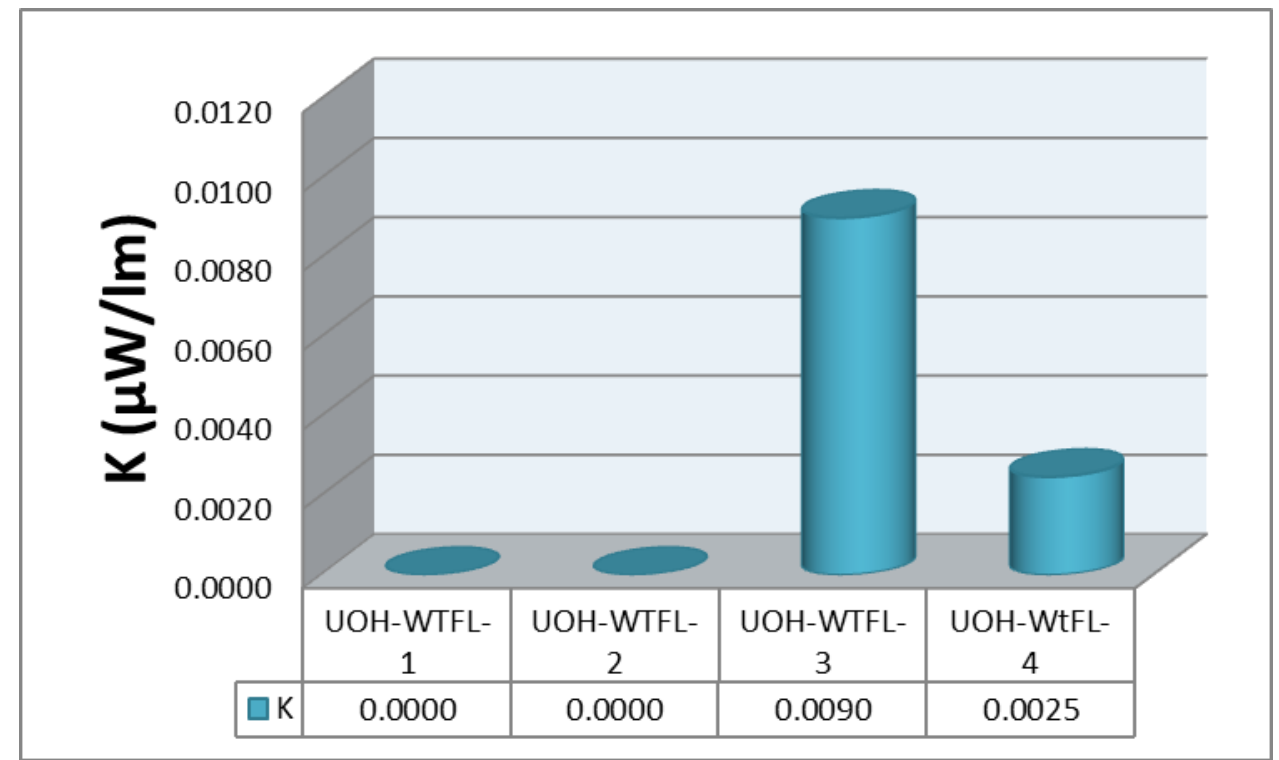

Fig. 9. UVA absolute irradiance levels per illuminace values (K) for WTFLs using calibrated UVA radiometer and luxmeter at 1 meter.

\section{UNCERTAINTY ANALYSIS}

Evaluation of the uncertainty is done by the Guide to the expression of uncertainty in Measurement (GUM) method. This method is adopted and described in details by International Organization for Standardization (ISO) [23]. The standard uncertainty $u\left(x_{i}\right)$ to be associated with input quantity $x i$ is the estimated standard deviation of the mean $[23,24]$

$$
u\left(x_{i}\right)=s(\bar{X})=\left(\frac{1}{n(n-1)} \sum_{k=1}^{n}\left(X_{i, k}-\bar{X}\right)^{2}\right)^{1 / 2}
$$

The combined standard uncertainty $u c(y)$ is obtained by combining the individual standard uncertainties $u_{i}$ these can be evaluated as Type A and Type B. That is,

$$
u_{c}^{2}(y)=\sum_{i=1}^{N}\left(\frac{\partial f}{\partial x_{i}}\right)^{2} u^{2}\left(x_{i}\right)
$$

Uncertainty model used for the determination of the UVA irradiance $E_{U V A}(\lambda)$ is $[14,25]$ :

$$
E_{U V A}(\lambda)=E_{S}(\lambda)+\delta E_{l}+\delta E_{r}
$$

where, $E_{S}(\lambda)=$ uncertainty due to reference spectral irradiance UVA standard radiometer (obtained from the calibration certificate).

$\delta E_{l}=$ uncertainty due to distance effect on the irradiance measurements (calculated by using the inverse square law). 
$\delta E_{r}=$ uncertainty due to repeatability of the measurements (standard deviation of repeated 5 times).

The uncertainty must be quoted whenever the results of a measurement are reported, it tell us about the precision with which the measurements were made. The uncertainty budget of the absolute irradiance and illuminance measurements are shown respectively in Table 1 and Table 2 with expanded uncertainty with confidence level $95 \%$ (coverage factor $\boldsymbol{k}=$ 2). Finally, UVA irradiance, and illuminance measurements are calculated. As discharge lamps are lesser stable in terms of electrical current and output values, in comparison to incandescent lamps, these output values exhibit larger uncertainties.

Table 1: Estimated Uncertainty budget of UVA irradiance for WTFLs.

\begin{tabular}{|l|l|}
\hline Uncertainty Component & $\begin{array}{l}\text { Relative Standard } \\
\text { Uncertainty (\%) }\end{array}$ \\
\hline $\begin{array}{l}\text { Irradiance responsivity calibration } \\
\text { of standard radiometer }\end{array}$ & 5.2 \\
\hline Distance measurements & 0.010 \\
\hline Repeatability & 0.02 \\
\hline $\begin{array}{l}\text { Relative Expanded Uncertainty } \\
(\boldsymbol{k}=\mathbf{2})\end{array}$ & $\mathbf{1 0 . 4}$ \\
\hline
\end{tabular}

Table 2: Estimated Uncertainty budget of illuminance for WTFLs.

\begin{tabular}{|l|l|}
\hline Uncertainty Component & $\begin{array}{l}\text { Relative Standard } \\
\text { Uncertainty (\%) }\end{array}$ \\
\hline $\begin{array}{l}\text { Illuminance responsivity } \\
\text { calibration of standard photometer }\end{array}$ & 6 \\
\hline Distance measurements & 0.015 \\
\hline Repeatability & 0.02 \\
\hline $\begin{array}{l}\text { Relative Expanded Uncertainty } \\
(\boldsymbol{k}=\mathbf{2})\end{array}$ & $\mathbf{1 2}$ \\
\hline
\end{tabular}

\section{CONCLUSION}

Measurements for UVA content present in the radiation of three different brands of white tubular fluorescent lamps (WTFLs) commonly used in Saudi Arabia markets and Hail University in indoor lighting were studied to assess their unwanted output in the UVA region and their illuminance level. The irradiance and illuminance values of WTFLs measured at distance of 0.5 meter and 1 meter using calibrated Sper Scientific UVA/B Light Meter (Model 850009C) UVA and luxmeter to obtain irradiance levels per illuminace values. The measurements were performed under control of environmental conditions. Various parameters such as ultra violet irradiance (UVA), ratio of UVA irradiance to electrical power $(\eta)$ and ratio of UVA power to luminous flux $(\mathrm{K})$, for the four of WTFLs are studied to dedicate their performance. A set up based on UVA/B silicon detector for irradiance $\left(\mathrm{W} / \mathrm{m}^{2}\right)$ measurements in UVA region. Second set up for Luxmeter is used for measuring illuminance. For all three different brands under study, $\mathrm{K}$ parameter remains less than the safe limit for human health [12]. YAMANY -18 Watt WTFLs have the smaller ratio $(\eta)$ than Philips 18 Watt WTFLs. ELETRA -36 Watt WTFLs have the smaller ratio (n) than Philips 36 Watt WTFLs. According to our results, we recommended using YAMANY -18 Watt than Philips 18 Watt at short distance in table lamps or other applications and the distance more than 0.5 meter. Also, we recommended using ELETRA -36 Watt than Philips 36 Watt at short distance in table lamps or other applications and the distance more than 1 meter. Data analysis was performed. Uncertainty model includes all parameters accompanied with the measurements are studied. The accompanied uncertainty in the absolute UVA irradiance measurements $(10.4 \%)$ and in the illuminance measurements $(12 \%)$ are calculated respectively in Table. 1 and Table. 2 with confidence level $95 \%(k=2)$.

\section{REFERENCES}

[1]. P. Waide and S. Tanishima, Light's Labour's Lost: Policies for Energy-Efficient Lighting, OECD Publishing, 2006.

[2]. "General discussion on energy saving," in Proceedings of the 1st International Conference on Power Electronics Systems and Applications, D. H. Wang and K.W. E. Cheng, Eds., pp. 298-303, IEEE, November 2004.

[3]. Comission Internationale de Eclairage. Electric Light Sources State of Art-1987, CIE 77, 1988.

[4]. I. Abdel Gelil, "Regional report on efficient lighting in the Middle East and North Africa," Tech. Rep., Division of Global Environment Facility Coordination, United Nations Environment Programme, Nairobi, Kenya, 2011.

[5]. Shahram Safari et al., "Ultraviolet Radiation Emissions and Illuminance in Different Brands of Compact Fluorescent Lamps ", International Journal of Photoenergy, volume 2015.

[6]. D. Parsons, "The environmental impact of compact fluorescent lamps and incandescent lamps for Australian conditions," The Environmental Engineer, vol. 7, no. 2, pp. 8-14, 2006.

[7]. C. Cole, P. D. Forbes, R. E. Davies, and F. Urbach, "Effect of indoor lighting on normal skin," Annals of the New York Academy of Sciences, vol. 453, pp. 305-316, 1985.

[8]. A. D. Nuzum-Keim and R. D. Sontheimer, "Ultraviolet light output of compact fluorescent lamps: comparison to conventional incandescent and halogen residential lighting sources," Lupus, vol. 18, no. 6, pp. 556-560, 2009.

[9]. R. M. Sayre, J. C. Dowdy, and M. Poh-Fitzpatrick, "Dermatological risk of indoor ultraviolet exposure from contemporary lighting sources," Photochemistry and Photobiology, vol. 80, no. 1, pp. 47-51, 2004.

[10]. M. J.Whillock, A. F. McKinlay, J. Kemmler, and P. G. Forsgren, "Ultraviolet radiation emissions from miniature (compact) fluorescent lamps," Lighting Research and Technology, vol. 22, no. 2, pp. 125-128, 1990.

[11]. M. Havas, Health Concerns Associated with Energy Efficient Lighting and Their Electromagnetic Emissions, vol. 3, SCENIHR \& Light Sensitivity, 2008.

[12]. Parag Sharma, V.K. Jaiswal, H.C. Kandpal, "Ultraviolet Radiation Emitted by Compact Fluorescence Lamps", J. Metrol. Soc. India (MAPAN) 24, 183-191 (2009). 
[13]. C. De Cusatis, Handbook of Applied Photometry (Optical Society of America, Poughkeepsie, New York, 1994).

[14]. E. El-Moghazy, A.-E.A. Abd-Elmageed_, and S. Reda,

" Measurements of UV-A radiation and hazard limits from some types of outdoor lamps", Int. J. Metrol. Qual. Eng. 5, 407 (2014).

[15]. ACGIH, TLVs and BEIs Based on the Documentation of the Threshold Limit Values for Chemical Substances and Physical Agents, and Biological Exposure Indices, ACGIH, Cincinnati, Ohio, USA, 2008.

[16]. B. L.Diffey, "Sources and measurement of ultraviolet radiation," Methods, vol. 28, no. 1, pp. 4-13, 2002.

[17]. National Lighting Product Information Program, "Screwbase compact fluorescent lamp products," Specifier Reports, vol. 7, no.1, p. 4, 2005.

[18]. Whillock M, McKinlay A, Kemmlert J, Forsgren P. Ultraviolet radiation emission from miniature compact fluorescent lamps. Lighting Res Technol; 22(3):125128,1990 .

[19]. European Standard EN13032-1:2004. Light and lighting. Measurement and presentation of photometric data of lamps and luminaires. Measurement and file format.

[20]. F. Grum, R. Becherer, Optical Radiation Measurements (Academic Press, Radiometry, 1979), Vol. 1. [21]. Manal A. Haridy, Sameh M. Reda, Abdel Naser Alkamel Mohmed, "Illuminance and Ultra Violet Emissions Radiated from White Compact Fluorescent Lamps", Int. J. Metrol. Qual. Eng. 7, 407 (2016).

[22]. International Commission on Non Ionizing Radiation Protection (ICNIRP).Guidelines on limits of exposure to ultraviolet radiation of wavelength between $180 \mathrm{~nm}$ and 400 nm. Health Phys.; 87(2):171-186,2004.

[23]. International Organization for Standardization (ISO), Guide to the expression of uncertainty in measurement (1993).

[24]. United Kingdom Accreditation Service (UKAS), The expression of uncertainty and confidence in measurement, 2nd edn. (2007).

[25]. Samaa M. El-faramawy, Sameh M. Reda , Alaa Eldin Ahmed Abd- Elmaged, Rem H. El-gebaly, A. SoltanMonem "Radiometric Technique to Assess the Qualification of Phototherapy Luminaire for Jaundice Treatment", Medical Science, Volume 5, Issue :, pp. 428430, 7 , July 2015. 